\title{
Erratum to: Monte Carlo dosimetry of the IRAsource high dose rate ${ }^{192}$ Ir brachytherapy source
}

\author{
Akbar Sarabiasl $^{1} \cdot$ Navid Ayoobian $^{1} \cdot$ Hossein Poorbaygi $^{2} \cdot$ Iraj Jabbari $^{1} \cdot$ \\ Mohammad Reza Javanshir ${ }^{2}$
}

Received: 17 September 2015/Accepted: 17 February 2016/Published online: 26 April 2016

(c) Australasian College of Physical Scientists and Engineers in Medicine 2016

\section{Erratum to: Australas Phys Eng Sci Med DOI 10.1007/s13246-016-0429-y}

Above mentioned paper has been published online with only the name of the corresponding author. Due to circumstances the names of the co-authors were omitted from the author group.

The complete author group should read Akbar Sarabiasl, Navid Ayoobian, Hossein Poorbaygi, Iraj Jabbari, Mohammad Reza Javanshir.

Above mentioned co-authors have been added to the author group.
To safeguard the integrity of information once an article has been published in On-line First and allocated a citable DOI, ethical and publication guidelines request the publication of an erratum in case of post-publication corrections.

The erratum also informs all parties involved about the correction such as indexing \& abstracting services, journal subscribers and readers who have bought and/or downloaded a copy of the article.

The online version of the original article can be found under doi:10.1007/s13246-016-0429-y.

Akbar Sarabiasl

a.sarabias1@ast.ui.ac.ir

1 Department of Nuclear Engineering, Faculty of Advanced Science \& Technologies, University of Isfahan, 81756-73441 Isfahan, Iran

2 Nuclear Science Research School, Nuclear Science and Technology Research Institute NSTRI, Tehran, Iran 